\title{
REPUTATION WHEN THREATS AND TRANSFERS Are AVailable
}

\author{
ERNESTO DAL Bó \\ Stanford Graduate School of Business and NBER \\ Stanford University \\ Stanford, CA 94305 \\ Dal-Bo_Ernesto@GSB.Stanford.edu \\ Pedro Dal Bó \\ Department of Economics \\ Brown University \\ Providence, RI 02912 \\ PDalBo@Brown.edu \\ RAFAEL Di TELLA \\ Harvard Business School and NBER \\ Soldiers Field \\ Boston, MA 02163 \\ rditella@hbs.edu
}

We present a model where a long run player is allowed to use both money transfers and threats to influence the decisions of a sequence of short run players. We show that threats might be used credibly (even in arbitrarily short repeated games) by a long-lived player who gains by developing a reputation

of carrying out punishments. Particular cases of the model are a long-lived pressure group offering rewards and punishments to a series of targets (public or corporate officials) in exchange for policy favors, or that of a long-lived extorter who demands money in order not to punish. We use the model to analyze the "convicted nonpayor" debate around judicial corruption. The model highlights formal similarities between lobbying and extortion.

\section{INTRODUCTION}

We study a long run player seeking to affect the decisions of a finite series of short run players by using both transfers and threats. Of course, a problem with threats is that they may not be credible. We construct

We thank two anonymous referees, David K. Levine, Hongbin Cai, and participants at the Business and its Social Environment 2006 conference at Stanford GSB for useful comments, as well as David Austen Smith for discussion of the paper. 
an equilibrium in which the long run player develops a reputation for carrying out her threats as in Kreps and Wilson (1982) and Milgrom and Roberts (1982). ${ }^{1}$ We find that the existence of a second instrument that is continuous, such as monetary transfers, allows the long run player to profit from her reputation more easily than without transfers. Even for an arbitrarily small amount of asymmetric information and a small number of short run players (as low as two), the long run player obtains positive profits from reputation.

The model helps understand how transfers and threats can be used simultaneously, and how, when the power to inflict damage is high enough, the long run player may demand, rather than offer, payments. This suggests that-at least in a formal dimension-the difference between lobbying and extortion, and between interest groups and mafias, may be one of degree rather than nature. ${ }^{2}$

A particular case of this model is that of a long-lived lobby (or pressure group) facing a sequence of officials from whom a particular policy position is demanded. The ability of the pressure group to credibly use threats saves on bribe payments or other rewards that are continuous (like money or praise). Pressure groups may threaten their targets (a government, a firm, or individual officials) with various forms of damage. Relevant examples are physical violence, legal harassment, smear campaigns in the media, or boycotts and other forms of direct action campaigns. To the extent that carrying out such retaliations is costly, delivering on a threat is a dominated strategy in the stage game. In our repeated game, however, reputational concerns will push pressure groups to keep their word. The model predicts that groups with more virulent punishment technologies and with lower costs of delivering punishment will find it easier to sustain a reputation for honoring their threats, and will in equilibrium punish more often. The model helps generate a taxonomy of pressure groups depending on the strength of the punishments utilized. This could help organize discussion around the issue of what we understand by radical groups along the dimension of tactics rather than agendas. This prediction may help understand why some former officials find lucrative jobs in lobbying. These individuals, through their contacts and insider knowledge, may contribute to a pressure group's ability to deliver punishments in a cost-effective manner. Such individuals may know the vulnerabilities of active officials (i.e.,

1. See also Rosenthal (1981) for an early contribution on how uncertainty could sustain the use of punishment. Mailath and Samuelson (2006, Ch. 17) offer a unifying treatment of the literature on "chain-store" reputation models as well as useful references.

2. In other words, the "twin faces" of judicial corruption described in Ayres (1997) as bribery and extortion can be seen as part of the same incentive problem. For a discussion of blackmail and bribery, see Lindgren (1988) and section IV in Landes and Posner (1975). 
they know what will hurt). Lastly, the model predicts that reputationenhancing elements will be valuable to the group. Thus, activist groups may want to enroll members with known track records in direct action campaigns. This may explain why certain activist groups (like, say, Shepherds of the Sea) feature the militant trajectory of their leaders prominently, and why we should expect to see a labor market for activists and lobbyists where track records matter.

Another particular case of the model is that of a long-lived judge extorting money from defendants in exchange for not passing a worsethan-deserved conviction. This allows us to discuss the "convicted nonpayor problem," where defendants that didnot pay bribes to a corrupt judge got heavier-than-deserved sentences. A fascinating discussion is contained in Ayres (1997), where he explains that convicted nonpayors should be granted new trials. This opinion was not shared by Judge Posner, who intervened in the case and who doubted that a judge taking bribes from payors should have incentives to impose worse-than-deserved sentences on non-payors. Our model tracks the reasoning in Ayres (1997): a judge seeking to extract higher bribes from future defendants has an incentive to develop a reputation for "toughness" on those defendants that do not pay bribes. Our model formally demonstrates this proposition even for cases in which the judge may have a short time horizon and a low initial reputation for toughness. We discuss this application in Section 6, but it is worth noting here that, as Ayres (1997, p. 1247) stated, "At this point it might be useful to point out that Judge Maloney sentenced more people to death than any other judge in Cook County."

The structure of the paper is as follows. Section 2 reviews some related literature. Section 3 presents our model of influence through both rewards and punishments. Section 4 constructs a Sequential Equilibrium in which threats become endogenously credible. Section 5 presents the problem of the "nasty" pressure group and explains the relationship between the use of threats and cheap bribes. Section 6 presents the problem of judicial extortion, describes the legal debate around it, and explains how our model contributes to it. Section 7 concludes.

\section{RELATED Literature}

There is a large literature on political influence, starting with work by the Virginia and Chicago Schools (see, for example, Buchanan et al., 1980; Stigler, 1971). One strand of the ensuing literature has focused on the informational value of lobbying (see, for example, Austen Smith, 1987; Lohmann, 1995). A smaller part of this literature has discussed the interaction between information and incentives, both positive (Bennedsen 
and Feldmann, 2002) and negative (Sloof and Van Winden, 2000). ${ }^{3}$ Another strand of the influence literature has focused exclusively on incentives, which can affect the utility of the recipient positively (as with bribes) or negatively (as with punishments). Work along these lines includes models were only positive incentives are used, such as, inter alia, Baron (1989), Bernheim and Whinston (1986), and Grossman and Helpman (1994). Another family of models focuses on negative modes of influence, such as the model of "capture by threat" of Dal Bó and Di Tella (2003), the model of minimal squawk by Leaver (2003), and the models of private politics of Baron (2001) and Baron and Diermeier (2005).

Dal Bó et al. (2006) bridge the gap between models of political influence considering only positive or negative incentives. They integrate the use of both, and derive implications for the quality of public officials and the role that immunity from legal prosecution may have at mitigating political influence. Baron and Diermeier (2005) utilize a related framework to analyze private politics and generate a wealth of predictions regarding the interaction of corporations and activists. Chwe (1990) contains a pioneering treatment of the integrated use of rewards and pain-in his model, the focus is on giving incentives to workers. These models assume that threats of punishment are credible.

In this paper, we no longer assume that threats are exogenously credible, but study the possibility that their credibility emerges endogenously although transfers are available. The model of repeated interaction we use is an extension of Kreps and Wilson (1982). We allow the (finitely lived) long run player an extra (continuous) instrument: money transfers-which could be either bribe offers or requests. This is appealing because the assumption that only punishments are available is restrictive; in most instances players will have the ability to make transfers, so we would like to know how this affects reputation building. It also changes the problem of the long run player in a way that allows her to benefit from the possibility of building up a reputation even in short games. In Kreps and Wilson's paper, for any given value of the initial prior, the game has to be long enough for the possibility of reputation building to have a positive impact on the long run player's payoff. See also Milgrom and Roberts (1982), Kreps et. al. (1982) and Chapter 17 in Mailath and Samuelson (2006). In models à la Kreps and Wilson equilibrium is essentially unique and yields the long run player Stackelberg payoffs. The equilibrium we construct is the direct extension of that equilibrium in the case in which transfers are possible. Multiple equilibria may arise depending on the beliefs held

3. We are grateful to David Austen Smith for pointing us toward the latter work. 
by short run players following different transfers. The equilibrium we focus on may be deemed focal in that it captures the intuitive situation in which the long run player benefits from reputation (as opposed to the counterintuitive case highlighted by the chain-store paradox).

Other authors have noted that extortionary pressures run into a credibility problem. Konrad and Skaperdas (1997) study a model where the extorter commits to carry out punishments because it is possible to generate commitment by sinking costs in advance. In contrast, in our model reputation arises exclusively from honoring one's promises. Smith and Varese (2001) explore a related model with only two periods, analyzing the possibility that fake mafia members might mimic real mafiosi when attempting to charge for protection. Our model provides a general multiperiod framework and has a more generic extensive form highlighting the formal connections between lobbying and the functioning of mafias. Shavell and Spier (2002) study the credibility of threats for cases in which the threatening party faces either a short run incentive or a short run cost to carry out the punishment. For the first case and in an infinite horizon game in which the threat can only be carried out once, they show that the threatener can credibly commit to not carry out the punishment if she receives the payment.

We show that both rewards and punishments are used by interest groups in equilibrium and that the use of punishments saves on rewards. This is related to a phenomenon that has puzzled political economists who have observed unequal exchange of favors to often take place in the political arena (see, for example, Tullock, 1997). ${ }^{4}$ Finally, our model is related to work in conflict theory (see, for instance, Garfinkel, 1990; Skaperdas, 1992; Powell, 1993; Hirshleifer, 2001), where the possibility of coercion has traditionally been included.

\section{THE MODEL}

There are $N+1$ players in this game: one long run player $(L R)$ and $N$ short run ones, with the typical short run player denoted $S R_{n}, n=$ $1,2, \ldots, N$. The long run player sequentially plays the game in Figure 1 against one short run player at a time, starting with $S R_{N}$ and ending with $S R_{1}$, following the reputation literature convention. The objective of $L R$ is to obtain a favor from each short run player, the value of which is $\pi$.

Nature determines the type of both $L R$ and the short run players. $L R$ knows that every short run player she meets is "sane" with

4. For other models where little or no money changes hands in the political influence process, see Ramseyer and Rasmusen (1992), Helpman and Persson (2001), Dal Bó (2000), and Leaver and Makris (2001). 


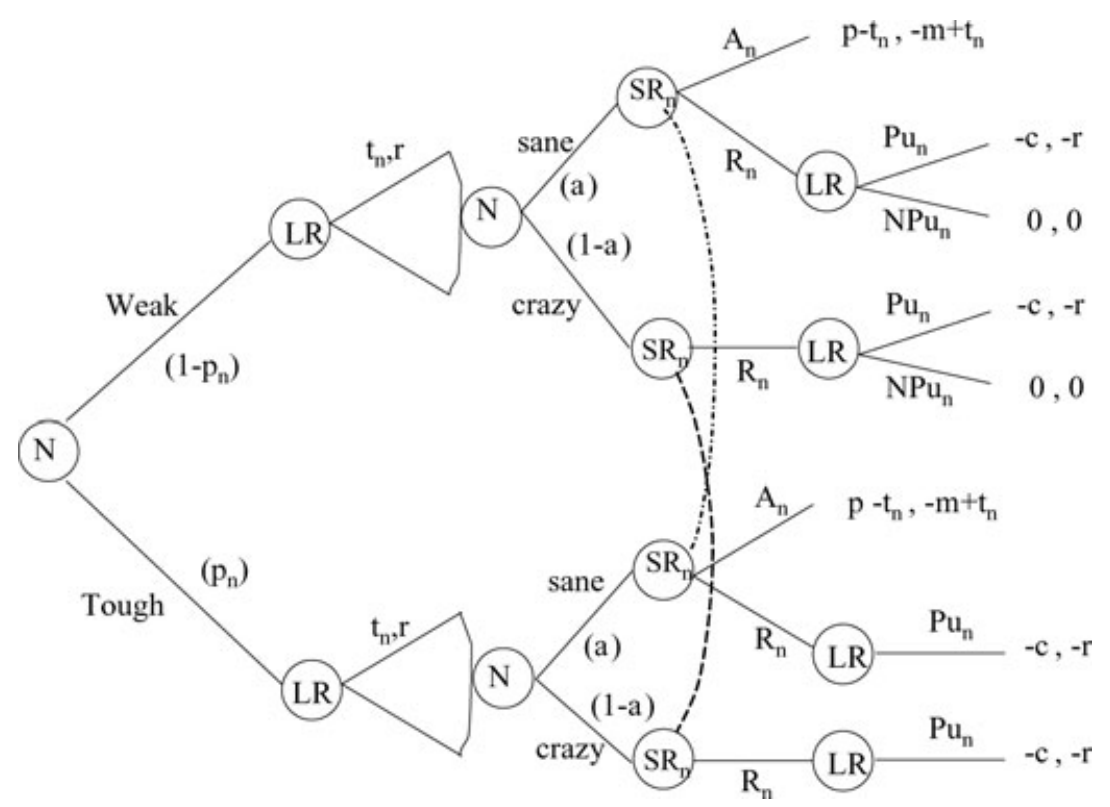

FIGURE 1. STAGE GAME

probability $\alpha$ and "crazy" with probability $1-\alpha$. Moreover, $L R$ is "tough" with probability $p_{N}$ and "weak" with probability $1-p_{N}$. The short run players observe all previous play but do not know the type of $L R$. They may have beliefs regarding her type and we denote the belief held by $S R_{n}$ as $p_{n}$.

At stage $n$, both types of $L R$ can offer a transfer (which can be positive or negative) denoted by $t_{n}$ in exchange for a favor from $S R_{n}$. The value $\pi$ of a favor can be thought to be net of any costs that offering a transfer might entail (such as the expected cost of apprehension if the transfer is illegal). A sane $S R_{n}$ may accept $\left(A_{n}\right)$ or reject $\left(R_{n}\right)$ the offer. A crazy $S R_{n}$ can only reject the offer. If the sane $S R_{n}$ accepts, $L R$ earns a profit $\pi$ from the deal and pays the transfer $t_{n}$ (actually earns the transfer if $t_{n}$ is negative). If $S R_{n}$ rejects the offer, $L R$ has access to a punishment technology $\left(P u_{n}\right)$, which, at a fixed cost $c$, inflicts a utility loss of fixed size $r$ on the short run player. ${ }^{5}$ Thus, at stage $n$ what $L R$ does is to offer a menu of a transfer $t_{n}$ and a threat of retaliation $r$. In words, $L R$ could tell $S R_{n}$ "Grant me a favor and receive $t_{n}$, or I will inflict a loss $r$ on

5. Here we follow the convention in the chain-store literature that considers a fixed punishment. Note that this is convenient because it fixes the actions of the behavioral or "tough" type, and then one can study the incentives that normal players have to mimick such behavior. 
you." A difference between tough and weak types is that the weak type has an option to retaliate at a cost $c$. The tough type has no option but to respond to any refusal from $S R_{n}$ by retaliating. One can think of the tough type as one that responds viscerally to refusals by irrationally punishing all refusals, even if this is just as costly to him as it is for the weak type.

Sane short run players receive a utility of $t_{n}-m$ for accepting the offer of LR (where $m$ is the moral cost of being bought or the expected cost of being caught) and a disutility of $r$ if they are punished by $L R$ after rejecting her offer. We assume that $c$ and $r$ are strictly positive. Nothing changes when considering time-dependent values for $\pi, m, c$, and $r$, apart from complicating notation. For analytical simplicity we assume that $\pi \geq m$ and $\alpha r>c$. $^{6}$

As an example of this game, think of an industry lobby asking officials from different regions to issue a permit allowing the realization of a socially undesirable project in each region. The project yields the industry a return $\pi$ for each territory where it is allowed. The industry lobby can use both bribes and threats to convince each official to issue the permit. In Section 6, we show how the model can also be used to explain the credibility of threats in blackmail and extortion. For expositional simplicity, although describing and discussing the equilibrium we will refer to transfers as money paid by the long run player to the short run players. As we will show, however, whether the long run player offers or requests payments is endogenously determined.

\section{Reputational Equilibrium}

In this section, we present a sequential equilibrium of the game in which a reputation effect may arise. The equilibrium is of great simplicity because $p_{n}$ is a sufficient statistic of the history of the game. Therefore, strategies can be written solely as a function of beliefs in each stage (and the stage number) instead of as a function of past history. In addition, only $L R$ eventually randomizes.

Consider the following profile of actions and beliefs:

Strategies:

(i) For the short run player in period $n\left(S R_{n}\right)$ :

When Sane:

If $n=1$ :

$A_{1}$ if $t_{1} \geq m-p_{1} r, R_{1}$ otherwise.

If $n>1$ :

6. This last assumption, in particular, implies that $c<r$. The model admits a similar solution under a milder restriction that allows $c$ to be larger than $r$. The alternative version of the model is notationally more involved and is available from the authors upon request. 
If $p_{n}<\frac{c}{\alpha^{n-1}\left(\frac{r}{c}+1\right)^{n-2} r}: A_{n}$ if $t_{n} \geq m-p_{n} \alpha^{n-1}\left(\frac{r}{c}+1\right)^{n-2} \frac{r^{2}}{c}$,

$R_{n}$ otherwise

If $p_{n} \geq \frac{c}{\alpha^{n-1}\left(\frac{r}{c}+1\right)^{n-2} r}: A_{n}$ if $t_{n} \geq m-r, R_{n}$ otherwise

When Crazy: always $R_{n}$.

(ii) For the long run player $(L R)$ :

When Weak:

If $n=1$ :

$$
t_{1}=m-p_{1} r, N P u_{1} .
$$

If $n>1$ :

If $p_{n}<\frac{c}{\alpha^{n-1}\left(\frac{r}{c}+1\right)^{n-2} r}: t_{n}=m-p_{n} \alpha^{n-1}\left(\frac{r}{c}+1\right)^{n-2} \frac{r^{2}}{c}$,

$P u_{n}$ with probability

$$
\begin{aligned}
& \frac{p_{n}}{\left(1-p_{n}\right) c}\left[\alpha^{n-1}\left(\frac{r}{c}+1\right)^{n-2} r-c\right], \text { and } N P u_{n} \text { with probability } \\
& 1-\frac{p_{n}}{\left(1-p_{n}\right) c}\left[\alpha^{n-1}\left(\frac{r}{c}+1\right)^{n-2} r-c\right] . \\
& \text { If } p_{n} \geq \frac{c}{\alpha^{n-1}\left(\frac{r}{c}+1\right)^{n-2} r}: t_{n}=m-r, P u_{n}
\end{aligned}
$$

When Tough: Same transfers as Weak but always $P u_{n}$.

Beliefs:

$$
\begin{aligned}
& p_{n-1}=\frac{c}{\alpha^{n-1}\left(\frac{r}{c}+1\right)^{n-2} r} \text { if } 0<p_{n}<\frac{c}{\alpha^{n-1}\left(\frac{r}{c}+1\right)^{n-2} r} \text { and } P u_{n} \\
& p_{n-1}=p_{n} \text { if } A_{n} \text { or }\left[p_{n} \geq \frac{c}{\alpha^{n-1}\left(\frac{r}{c}+1\right)^{n-2} r} \text { and } P u_{n}\right] \\
& p_{n-1}=0 \text { if } N P u_{n} \text { or } p_{n}=0
\end{aligned}
$$

Proposition 1: The former strategies and beliefs define a sequential equilibrium of the game. 
Proof. See Appendix.

In equilibrium, a weak $L R$ always pays the short run players the minimum transfers they will accept, and the sane short run players always accept. In the last period a weak $L R$ does not punish a rejection and then must pay a transfer equal to $m-p_{1} r$. If $n>1$, the optimal action of $L R$ depends on the beliefs of the short run player. When the prior of the short run player is greater than $\frac{c}{\alpha^{n-1}\left(\frac{r}{c}+1\right)^{n-2} r}, L R$ punishes for sure a rejection. If the prior probability is lower than that level, a weak $L R$ randomizes. When the outcome of the randomization is not punishing, the long run player's type is revealed, leading to a posterior $p_{n}=0$. When the randomization results in punishment, the short run players' belief that $L R$ is tough is updated upwards and $L R$ pays lower transfers in the future. ${ }^{7}$ The reason why $L R$ randomizes when the prior $p_{n}$ is not high enough is as follows. Punishing for sure would lead to a posterior that equals the prior, because if the weak $L R$ punishes for sure, and so does the tough one, the observation of punishment leads to no updating of the prior. But if the prior is not very high, the future returns from keeping it at that level are not enough to compensate for the costs $c$ of delivering punishment. Hence, the weak type would not want to punish when doing so leads to an unchanged posterior. But if the weak type is known not to punish, the observation of punishment would convince future $S R$ players that $L R$ is tough, taking the posterior to its highest possible value of one (Bayes' rule implies that the lower the probability that the weak $L R$ punishes, the higher the posterior of toughness following punishment). In this case, engaging in the cost $c$ and delivering punishment would pay for itself in terms of future bribe savings, which are proportional to the perception of toughness. Hence, when the weak $L R$ is known to be punishing, doing so does not pay, although it does pay when the weak $L R$ is thought not to be punishing. It follows that $L R$ must randomize.

Just as it would happen in the model by Kreps and Wilson (1982), if the prior is above certain level, $L R$ wants to punish (fight, in their setting) for sure. If it is below that level, in equilibrium $L R$ punishes with some probability that allows it to build a reputation for being tough in case it does punish. The farther a short run player is (in the order of play) from the one who will play last, the more likely it becomes that a given initial prior will be high enough for $L R$ to be willing to punish with probability one. Moreover, for any positive initial prior $p_{N}$, there is a game which is long enough, that is, where $N$ is large enough - for a weak $L R$ to be willing to punish for sure.

7. As demonstrated in the proof above, after a randomization has taken place, the upward update is not large enough to make $L R$ willing to punish the next $S R$ for sure. 


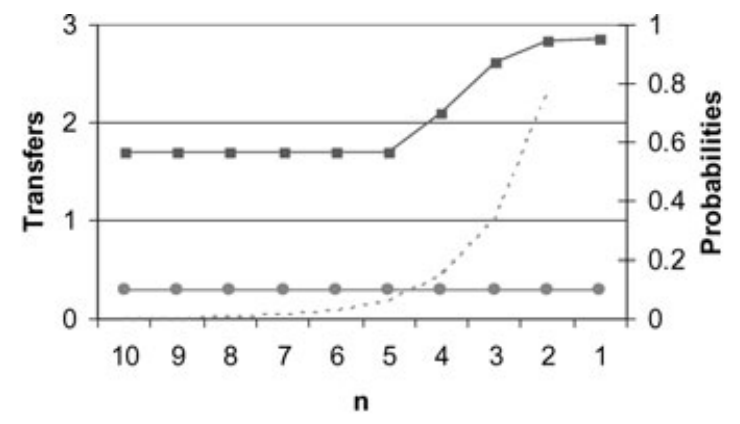

$\Longrightarrow$ transfer …... critical value $\longrightarrow$ tough probability

FIGURE 2. EQUILIBRIUM PLAY
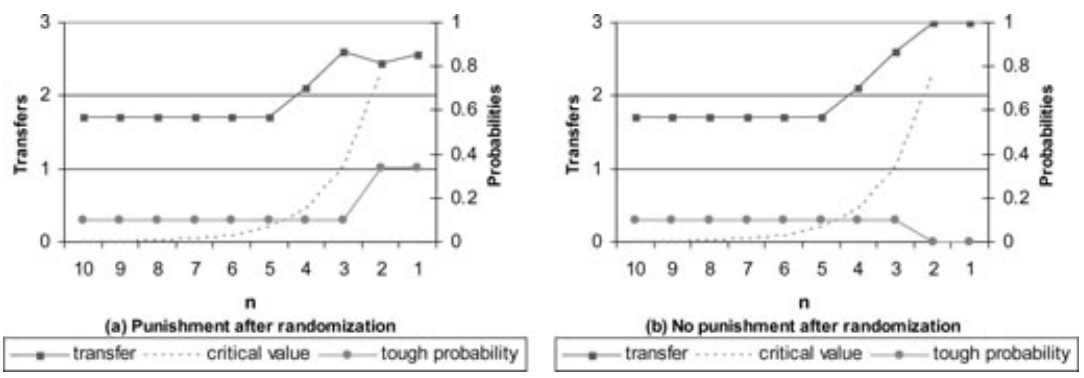

FIGURE 3. PLAY IN THE EVENT THAT THE SHORT RUN PLAYER REJECTS OFFER IN PERIOD 3

Figure 2 shows a typical path of play (for $\alpha=1, m=3, c=1, r=$ 1.3 , and $N=10$ ). It shows the dynamics of equilibrium transfers, beliefs and the critical value $\frac{c}{\alpha^{n-1}\left(\frac{r}{c}+1\right)^{n-2 r}}$ from Proposition 1. In periods 10-5, the prior is high enough that the long run player finds it advantageous to punish with probability one, in order to maintain a reputation for toughness. In this case, the long run player would punish with a probability less than one in case the short run player rejects the offer after period 5 . This decrease in the probability of punishment results in an increase in the equilibrium transfer. As the game nears its end, the probability of punishment decreases and the transfer increases.

Figure 3 shows the off-equilibrium path of play that arises if the official in period 3 rejects the transfer (in cases when $\alpha<1$ this could be part of equilibrium play when the $S R$ in period 3 is crazy). Panel (a) shows the off-equilibrium path when randomization by the $L R$ results in punishment, while panel (b) shows the case in which randomization results in no punishment. Punishment causes in an 
increase in the prior of the $L R$ being tough and results in lower transfers compared with the case in which the $L R$ does not punish and its type is revealed.

One interesting difference with the models due to Kreps and Wilson and Milgrom and Roberts is that in our setting the prior canwhile positive-be arbitrarily low and the long run player will still receive some benefits from the fact that it is punishing with positive probability. The reason is that punishing with positive probability lowers the transfer that buys a favorable decision from sane short run players. Clearly, the presence of a continuous instrument (transfers) is key for this result. From our Proposition, the equilibrium transfer by a weak long run player who enjoys a very low prior on toughness in period 2 $t_{2}=m-p_{2} \alpha \frac{r^{2}}{c}$. It is clear in this expression that no matter how low $p_{2}$ is, the long run player still benefits from the perception that he might be tough. Graphically, this effect can be seen in the equilibrium level of transfers represented in Figure 2. Note that the transfer in period 2 is lower than that in period 1, precisely because at that point the long run player is punishing with some probability and hence obtaining a "discount" on the price of favors. This does not happen in the basic chain-store model without side payments. In such model, if the prior is lower than a threshold level entry occurs and the incumbent does not benefit at all from the fact that it might punish entrants. The bottom line is that in the basic chain-store game a low enough initial prior means that the expected payoff of the long run player is zero. When transfers are available, the expected payoff of the long run player is positive, no matter how low the initial prior is-or, equivalently, no matter how short the game is. So while in Kreps and Wilson's model, given a prior, the game has to be long enough for some reputational benefit to accrue for sure to the long run player, in our set up the prior can be arbitrarily low and the game arbitrarily short (say with only two periods), and there still exists a reputational benefit: the long run player pays lower transfers. The implication is that it is not necessary for a long run player to be likely to stay around for a long time in order to reap some benefits in terms of low transfers.

It is well known that the reputational equilibrium in Kreps and Wilson (1982) is essentially unique (i.e., in terms of payoffs). This is not true of the game we analyze-one can construct examples where an arbitrary belief on the part of short run players may force the long run player to pay full transfers. Therefore, our model shows that long run players can benefit from reputation, but it does not guarantee that they will. However, we deem the equilibrium we have focused on to be quite focal and most likely a good prediction for the game. We discuss the issue of multiplicity further in the appendix. 
It is important to note that our equilibrium survives the application of a refinement such as the Intuitive Criterion. Note that for the equilibrium to be destroyed under such criterion, deviations would have to be "equilibrium dominated" for one of the types, so that the short run player should place zero probability on such a player having deviated. Then, one should check that under such beliefs the other type would be happy to deviate. More specifically, equilibrium dominance means that one of the two types of $L R$ would have to face losses when deviating from equilibrium play no matter what the response by the short run player is. But this is clearly not the case: any deviation to lower transfer offers, when met with acceptance, will yield a higher payoff to any type of $L R$ player. Deviations to higher offers will yield a lower payoff to both types. Therefore, the equilibrium we have characterized survives the Intuitive Criterion.

\subsection{IMPLICATIONS}

\subsubsection{Positive and Negative Transfers}

It is important to note that the long run player uses transfers and threats simultaneously to provide the desired incentives to the short run players. In fact, if the power of threats is high enough the transfers are negative. The long run player may not only obtain a favor with value $\pi$ from the short run player but also a monetary transfer when its retaliation power $r$ is large relative to the cost $m$ of yielding to the group's demand. Recall that in a typical period $n$, and depending on the level of the prior, the transfer is $t_{n}=m-p_{n} \alpha^{n-1}\left(\frac{r}{c}+1\right)^{n-2} \frac{r^{2}}{c}$ or $t_{n}=$ $m-r$. That is, whether the long run player pays bribes or extracts extortionary payments is a result of the reputational equilibrium and not a given. In this way, the equilibrium studied here highlights the formal connections between seemingly unrelated phenomena, such as lobbying and extortion. Mafias differ from lobbies in that they have a great capacity to inflict harm ( $r$ is high and $c$ is low) and in many occasions offer something in exchange (for instance, enforcement), making $m$ small. It can easily be seen that large $r$ and small $c$ and $m$ tend to make payments negative. Moreover, note that whenever $r>m$, reputation alone might make the difference between payments being positive or negative. In other words, a low enough reputation for toughness will make the long run player a "lobbyist" who pays for favors, while a high enough reputation will yield an exorter that extracts payments.

\subsubsection{The Length of Punishment Phases}

The threshold value above which the prior on toughness will justify punishing for sure is $\frac{c}{\alpha^{n-1}\left(\frac{c}{c}+1\right)^{n-2 r}}$. As illustrated in Figures 2 and 3, this 
level rises as the game approaches the last rounds. Note also that this threshold is increasing in the cost of punishment $c$ and decreasing in the disutility inflicted by punishment $r$. The higher the threshold, the sooner the long run player gets to the stage where he randomizes. The lower the threshold, the longer the part of the game where punishment occurs with certainty. Moreover, the probability of punishment in the randomizing phase reacts in a qualitatively similar way to changes in $r$ and $c$. Therefore, both a lower cost of punishment $c$ and a higher disutility from retaliation $r$ imply that more punishment will be observed.

\section{POLitical influence}

Direct relabeling of the model allows to think about interest groups (long run players) influencing sequences of government officials (short run players). Buying influence by transferring money to the officials is possible if the interest group will fully compensate officials for the disutility of doing it a favor. Such quid pro quo is (comparatively) simple to enforce, because the trade of money for a policy can be arranged to take place simultaneously. Using threats may save on transfer payments, but delivering a future punishment on an official that has refused to trade may be costly, and, hence, not credible. However, if the pressure group deals with more than one official, the results from the previous section show that there is an equilibrium in which the group develops a reputation for retaliating on those officials who reject bribes, which allows the group to pay low bribes. Similarly, activist groups targeting firms may obtain large changes in corporate policy in exchange for very scant public congratulation from the group (see also Baron and Diermeier, 2005 on why campaigns are typically negative). The real payoff to the corporation is the nonrealized punishment.

It has been argued that the bribes paid to officials in the public sector are usually of negligible value in comparison to the benefits they secure. Tullock (1980) expressed a puzzle regarding rent-seeking efforts that appear too small relative to the favors they secure. This came to be known as the "Tullock paradox." The model developed in this paper allows us to put forward an explanation for why politicians would require small compensation in exchange for their favors. In our view, the process of political influence is not limited to the offer of rewards in the form of gifts, courting, or bribes. Pressure groups may also want to give incentives through threats. When, for example, a group is influential enough so as to damage the future career of a politician, the latter may be inclined to concede favors to such group just to avoid its enmity. The existence of threats-even when in some cases they could be tacit-can explain why politicians are willing to sell their favors cheap. 
Although credibility of threats is no longer assumed, in our model a pressure group may develop a reputation for honoring its threats, allowing the group to pay cheap bribes. For other work on the topic of cheap bribes, see Ramseyer and Rasmusen (1992), Helpman and Persson (2001), Dal Bó (2000), Leaver and Makris (2001), and Dal Bó, Dal Bó, and Di Tella (2006). Note that the conditions for a pressure group to be able to profit from the use of threats are extremely weak. The only condition is that there exists a small amount of asymmetric information. In our model, contrary to the case of Kreps and Wilson (1982) and Milgrom and Roberts (1982), a pressure group can profit from developing a reputation even in a short horizon game-as short as two periods- for any arbitrarily small amount of imperfect information.

This is an interesting feature of our model because it implies that it is not necessary for a pressure group to be likely to stay around for a long time in order to reap some benefits in terms of cheap bribes. If the environment creates a positive prior in the officials' minds that a group is "nasty," then this group has incentives to punish honest officials with positive probability even when interacting with a small number of them. Of course, when a group is known to be influential and can be expected to face many officials, the potential for cheap bribes is larger.

In our model, reputation is built by exercising punishments. By highlighting the role of reputation and its dependence on the initial prior $p$, the model suggests that in reality there must exist complementary strategies that help raise the prior $p$. In the case of activist groups, one possibility is to incorporate activists with known records of direct action-this can help activist groups start the game with a prior that is high enough so that reputation-preserving punishments can be utilized in equilibrium with probability one. This will produce the maximum possible savings on rewards. In fact, this is one way to interpret the emphasis given by certain activist groups engaging in direct action (such as, for example, Shepherds of the Sea) to the "experience" of its leaders. This may be a way to shape the prior that targets hold on the probability that the group is willing to punish. In addition, this suggests that the trajectories of some activists and lobbyists should resemble those we observe in more standard labor markets: we should expect individual track records (experience) to matter and command a price that reflects some of the credibility value that these track records lend groups. (Because there is no comprehensive data on activist campaigns, testing these predictions is beyond the scope of this paper, but remains an interesting question for empirical research.) The model also predicts that lower costs of retaliation and more damaging punishment technologies should increase the number of periods in our finite game in which punishment is observed, making reputation easier to maintain, 
and saving the interest group money. This can help rationalize why former government officials usually find lucrative jobs in lobbying. Their contacts and insider knowledge may contribute to a lower cost of delivering punishment $c$ or to a higher retaliation power $r$.

\section{JUDICIAL EXTORTION}

Our model of transfers and threats can be applied to the general problem of extortion, and to the particular issue of judicial blackmail. We understand by this a situation in which a judge faces a sequence of defendants and can ask for a bribe in order not to impose a worse-thandeserved penalty. ${ }^{8}$ However, imposing excessive penalties on those defendants who refuse to pay bribes can be expected to be costly for the judge. For example, some judges must adhere to sentencing guidelines. Therefore, passing heavier-than-deserved penalties may require more elaborate (and hence more effort intensive) legal interpretations. Thus, a credibility problem arises. After a defendant refuses to pay the requested bribe, the judge may not have a short run incentive to impose a largerthan-fair sentence. However, if there is some amount of imperfect information on the judge's type, our model shows that the judge has an incentive to build a reputation for honoring his threats, no matter how low the prior on the judge's toughness or how short her time horizon. An important clarification is due: the toughness type the judge wants to signal is related to keeping his word and carrying out the threat of imposing a heavier-than-deserved sentence on nonpayors. It is not a type related to a legitimate judicial ideology favoring systematic higher sentences for given crimes. In this sense, judges have some leeway in choosing heavier sentences to the extent that there is something in the case that could justify a heavier sentence from a "harsh" enough judge. External monitors may not always be able to tell a judge that sometimes passes heavier sentences legitimately from one that does it to punish nonpayors. The fact that such identification is difficult but not necessarily impossible makes the situation facing the judge similar to a gamble. He has some room for pressuring defendants but delivering punishments to them is costly in expected terms, as captured by the model.

The form of judicial corruption involving the request of bribes in exchange for not passing a harsher sentence has recently been described

8. We use the "worse-than-deserved" terminology to maintain the language in Ayres (1997). Our model does not contain a benchmark of sentencing justice or deservingness. This implies that our model cannot be used to show that worse than deserved penalties are passed, but rather that sentences are passed that are worse than they would be in the absence of extortionary behavior. 
by Ayres (1997), who has first-hand experience on the topic. Ayres (1997, p. 1231) begins with "On January 25, 1990, I stood in a Cook County Circuit Court and accused the presiding judge, the Honorable Thomas J. Maloney, of extortion." Perhaps the most interesting part of Ayres (1997) is where he goes on to analyze the "convicted nonpayor" problem. ${ }^{9}$ That is, the problem of convicted defendants that did not pay bribes and got heavy sentences. He views this as a serious problem. In his words (p. 1233), "The United States Supreme Court is now grappling with the convicted nonpayor problem created by Judge Maloney's pattern of corruption. William Bracy and Roger Collins were convicted of murder and sentenced to death in a bifurcated jury trial over which Judge Maloney presided. [T]he defendants are seeking a new trial arguing that Judge Maloney's corruption in other cases gave him an incentive to be biased against defendants who did not pay him - in part to avoid suspicion that he was on the take."

One reason why, according to Ayres, Judge Maloney had an incentive to convict defendants who did not have a deal with him, was "to create a reputation as a tough judge so as to more easily extract money from defendants who did pay" (see page 1247). This argument is closely related to our model, as we explain further below. Our bribes and threats model shows that the judge does have an incentive to punish those who do not pay in order to extract higher payments from future defendants.

Judge Richard Posner, who intervened in the case, noted that a rule for automatic reversal in cases such as this may have large consequences because it "would thus require the invalidating of tens of thousands of civil and criminal judgements, since Judge Maloney alone presided over some 6,000 cases during the course of his judicial career..." ${ }^{10}$ More importantly, he did not see the merit in the argument that the judge's acceptance of bribes could have affected other cases where bribes were not paid. Judge Posner states "The fact that Maloney had an incentive to favor prosecution in cases in which he was not bribed does not mean that he did favor the prosecution in such cases more than he would have done anyway."11 Ayres (1997, p. 1248) is critical of this reasoning ("It is striking to hear one of the parents of law and economics argue that incentives don't on the margin affect behavior"). Our model formally demonstrates Ayres' argument above to be logically plausible.

In order to see this, we can consider the model in Section 3 with the long run player being the judge and the short run players being the defendants. If we assume that the judge does not ask for non pecuniary

9. The paper also discusses the acquitted-and convicted-payor problems.

10. Cited in Ayres (1997, p. 1248). See also Bracy v. Gramley, 81 F.3d 689; 1996 U.S. App.

11. See Bracy v. Gramley, 81 F.3d 689; 1996 U.S. App. 
contributions from the defendants and that the defendants do not face costs besides the amount of the transfer from the extortion payments, we can simplify the model by making $\pi=m=0$. Now $r$ denotes the disutility imposed on the defendant by a worse-than-deserved sentence, $c$ is the cost the judge faces when giving a worse-than-deserved sentence, and $-t_{n}$ is the extortionary payment made by the defendant $n$. We are agnostic in the model as to what represents a fair sentence. Given the judicial case, the judge always has the option of giving a tougherthan-deserved sentence at some cost in terms of stretching the juridic justification or facing a potential scandal. The rest of the parameters have the same interpretation as in Section 3. All mixing probabilities and equilibrium strategies in this game are as in Section 4. Then it is easy to see that "sane" defendants are willing to pay a positive amount of money to the corrupt judge to avoid a worse-than-deserved sentence. More importantly, the amount that "sane" defendants are willing to pay is increasing on the defendants belief that the judge is "tough," which gives the judge an incentive to punish those defendants that do not pay. The judge will develop a reputation for punishing those who do not pay by actually passing worse-than-deserved sentences. Note that with probability $1-\alpha$ each defendant will be "crazy" and thus punished in equilibrium. Hence, in equilibrium nonpayors will be convicted with worse than deserved sentences. Clearly the discovery that a judge has been on the take should trigger the revision of previous sentences. ${ }^{12}$

\section{CONCLUSION}

We study the credibility of private coercion when enticement is also possible. We provide a model where a long-lived player faces a finite sequence of short run players, as in Kreps and Wilson (1982) and Milgrom and Roberts (1982), but where the long run player may not only use threats of punishment but may also offer or request money transfers. We characterize a sequential equilibrium where the long run player develops a reputation for honoring his threats of punishing the short run players who do not accept his payment offers or requests. We show that the inclusion of a continuous choice variable like the money transfer allows the long run player to benefit from reputation even in arbitrarily short games. We apply the model to analyze both

12. The decision of The United States Court of Appeals for the Seventh Circuit that expressed the view that the accused had not shown good cause for discovery was reversed by the Supreme Court. However, the Supreme Court did not consider the reputation effect. See 520 U.S. 899; 117 S. Ct. 1793; 138 L. Ed. $2 d 97$. 
lobbying and extortion, highlighting the formal similarities between the two phenomena. Whether an organization with some coercive capability makes or extracts payments (or other kinds of favors) depends on the amount of damage it can inflict at a given cost. In other words, whether the long run player behaves as a lobby or a mafia is an endogenous result in our model.

We discuss two applications of our model. First, lobbies may develop a reputation for retaliating against officials that do not do favors to them. This reputation saves on bribes or other rewards that lobbies may direct to officials. The most obvious mechanism by which pressure groups construct such reputation is by exercising punishments and strategies that will help raise the prior $p$. The second application of the model is as a contribution to a legal debate on the "convicted nonpayor" problem that arises from judicial extortion. The implication of our model is that individuals convicted in trials conducted by judges who are later found to be on the take should be revised.

\section{APPENDIX}

Proof of Proposition 1. We have to check two things: first, that the beliefs are consistent with the strategies of the players and, second, that each of these strategies is a best response to other players' strategies in any stage of the game given the beliefs.

Beliefs are consistent. In this game we need only to study whether beliefs follow Bayes' rule whenever possible to check that they are consistent with the prescribed strategies. ${ }^{13}$ In addition, beliefs will not be modified by equilibrium bribes, because in equilibrium both types of $L R$ offer the same amount of bribe. Besides, we assume that deviations in the amount of transfers offered do not change beliefs. We assume that once the short run players believe with certainty that the pressure group is weak they do not modify their beliefs: $p_{n-1}=0$ if $p_{n}=0$. If $S R_{n}$ accepts the bribe no new information about $L R$ is revealed and then there is no update in beliefs: $p_{n-1}=p_{n}$ if $A_{n}$. If $S R_{n}$ rejects and is not punished, this shows that $L R$ is weak: $p_{n-1}=0$ if $N P u_{n}$. When $p_{n}>0$, punishments may modify beliefs. In any stage in which the weak $L R$ punishes with probability $\beta_{n}=\frac{p_{n}}{\left(1-p_{n}\right) c}\left[\alpha^{n-1}\left(\frac{r}{c}+1\right)^{n-2} r-c\right]$, the posterior beliefs can be calculated using Bayes' rule:

13. From Fudenberg and Tirole (1991) we know that the set of perfect Bayesian equilibria of this game coincides with the set of sequential equilibria. This implies that we only need to check that the beliefs conform to the application of Bayes' rule wherever possible. 


$$
p_{n-1}=P\left(\text { tough } / P u_{n}\right)=\frac{p_{n}}{p_{n}+\left(1-p_{n}\right) \beta_{n}}=\frac{c}{\alpha^{n-1}\left(\frac{r}{c}+1\right)^{n-2} r} .
$$

Strategies are best responses. We now check that the prescribed strategies for the short run players are best responses. Any sane short run player will accept the bribe only if its amount is enough to pay the moral cost minus the expected cost of a punishment: $A_{n}$ if $t_{n} \geq m-P\left(P u_{n}\right) r$, where $P\left(P u_{n}\right)$ is the probability of punishment if the bribe is not accepted. This probability is equal to $p_{n}$ if $n=1$; it is equal to $p_{n} \alpha^{n-1}\left(\frac{r}{c}+1\right)^{n-2} \frac{r}{c}$ if $n>1$ and $p_{n}<\frac{c}{\alpha^{n-1}\left(\frac{r}{c}+1\right)^{n-2} r}$, and equal to 1 if $n>1$ and $p_{n}>\frac{c}{\alpha^{n-1}\left(\frac{r}{c}+1\right)^{n-2 r}}$, leading to the sane short run players' strategies given above. Crazy short run players can only reject offers. Hence, doing so is a best response.

We can also verify that $L R$ is never going to offer more than the prescribed bribe because that would not affect the behavior of the short run players and would only result in a reduction of profits. Note that $\pi \geq m$, so, even at the cost of paying a full bribe $m, L R$ would be (weakly) better off than with a rejection. Thus, $L R$ will always prefer to pay transfers that guarantee acceptance by the sane short run players (according to their equilibrium strategy) rather than offering lower amounts that trigger rejections.

Now we check that the prescribed strategy for $L R$ is a best response given every history. To do this we proceed through a number of steps. First, note that a weak $L R$ does not punish rejections in the last period: punishing $\operatorname{costs} c$ and yields no return.

Second, we study the case of $n>1$. We describe a feature of the equilibrium in order to simplify the analysis. Regardless of the plays before $n$, if the equilibrium strategy prescribes that a weak $L R$ should randomize at $n$, the strategy will also prescribe randomizations for the following stages until $n=2$ or until the $L R^{\prime}$ s type is revealed. The reason for this is that if at $n$ a randomization was expected $\left(p_{n}<\frac{c}{\alpha^{n-1}\left(\frac{r}{c}+1\right)^{n-2} r}\right)$ and the outcome of this randomization was $P u_{n}$, then the posterior $p_{n-1}=\frac{c}{\alpha^{n-1}\left(\frac{r}{c}+1\right)^{n-2} r}<\frac{c}{\alpha^{n-2}\left(\frac{c}{c}+1\right)^{n-3} r}$ if $\alpha\left(\frac{r}{c}+1\right)>1$, which is implied by the restriction initially imposed on $\alpha$. Therefore, if $p_{n}<\frac{c}{\alpha^{n-1}\left(\frac{r}{c}+1\right)^{n-2 r}}$, a weak $L R$ should randomize after a rejection at any stage between $n$ and 2 (or until its type is revealed). We can now calculate inductively a weak $L R^{\prime}$ s payoff in equilibrium for any such period: $U_{n}^{P G}\left(p_{n}\right)=$ $n \alpha(\pi-m)+p_{n} \alpha^{n}\left(\frac{r}{c}+1\right)^{n-1} r$. If $S R_{n}$ rejects the bribe, $L R$ may punish him, triggering the updating of beliefs, or not punish him, revealing its type. As we calculate in the following equations, both actions yield the same payoff for a weak $L R$, so that randomization is a best response: 


$$
\begin{aligned}
U_{n}^{L R}\left(P u_{n} / R_{n}, p_{n}\right)= & -c+U_{n-1}^{L R}\left(p_{n-1}\right) \\
= & -c+(n-1) \alpha(\pi-m)+p_{n-1} \alpha^{n-1}\left(\frac{r}{c}+1\right)^{n-2} r \\
= & -c+(n-1) \alpha(\pi-m)+\frac{c}{\alpha^{n-1}\left(\frac{r}{c}+1\right)^{n-2}} \alpha^{n-1} r \\
& \times\left(\frac{r}{c}+1\right)^{n-2} r=(n-1) \alpha(\pi-m) . \\
U_{n}^{L R}\left(N P u_{n} / R_{n}, p_{n}\right)= & 0+U_{n-1}^{L R}(0)=(n-1) \alpha(\pi-m) .
\end{aligned}
$$

Now we check that a weak $L R$ is willing to punish rejections with probability one when $p_{n} \geq \frac{c}{\alpha^{n-1}\left(\frac{r}{c}+1\right)^{n-2} r}$. In order to do this, it is enough to analyze the case in which $\frac{c}{\alpha^{n-2}\left(\frac{r}{c}+1\right)^{n-3} r} \geq p_{n} \geq \frac{c}{\alpha^{n-1}\left(\frac{r}{c}+1\right)^{n-2} r}$, that is, the last stage in which a weak $L R$ punishes a rejection with probability 1 . This is so because in the previous periods a weak $L R$ would have an even higher incentive not to reveal its type. If $S R_{n}$ rejects the bribe a weak $L R$ 's payoffs are:

$$
\begin{aligned}
U_{n}^{L R}\left(P u_{n} / R_{n}, p_{n}\right)= & -c+U_{n-1}^{L R}\left(p_{n}\right)=-c+(n-1) \alpha(\pi-m) \\
& +p_{n} \alpha^{n-1}\left(\frac{r}{c}+1\right)^{n-2} r . \\
U_{n}^{L R}\left(N P u_{n} / R_{n}, p_{n}\right)= & 0+U_{n-1}^{L R}(0)=(n-1) \alpha(\pi-m) .
\end{aligned}
$$

Therefore, $P u_{n}$ is the best response given that $p_{n} \geq \frac{c}{\alpha^{n-1}\left(\frac{r}{c}+1\right)^{n-2} r}$.

\section{A. 1 MULTIPLE EQUilibria}

The models by Kreps and Wilson (1982) and Milgrom and Roberts (1982) feature an equilibrium that is essentially unique. In our model the issue of uniqueness is complicated by the existence of transfers. The reason is that the definition of sequential equilibrium does not provide tight enough restrictions on off-the-equilibrium beliefs after a deviation in the offer of transfers (restrictions like the Intuitive Criterion-due to Cho and Kreps, 1987-do not help here). For example a transfer $t=m$ can be supported in a sequential equilibrium because the short run player may believe that any deviation in transfers reveals that the long run player is weak. 
However, we deem the equilibrium we have characterized on to be quite focal, in that it provides a direct extension of the equilibria supporting Stackelberg payoffs to the case with transfers. In assessing the focality of such outcome it is worth recalling that the expression "chain-store paradox" was coined because most people would not expect the unraveling that occurs in finite games with no asymmetric information. Rather, most people would expect the long run player to benefit from its status. The work by Kreps and Wilson (1982) and Milgrom and Roberts (1982) resolved the paradox by making the outcome that yields Stackelberg payoffs (the outcome that most would expect) an equilibrium. Fudenberg and Levine (1989) study a wider class of games, including the chain-store model, and show that the payoffs to the long-run player converge to Stackelberg payoffs in any Nash equilibrium as the game gets sufficiently long, further reinforcing the resolution of the paradox. Our equilibrium provides a direct extension to the case with transfers of the equilibrium in those papers, which is the "expected" outcome. It is in this sense that we regard our equilibrium as focal.

\section{REFERENCES}

Ayres, I., 1997, "The Twin Faces of Judicial Corruption: Extortion and Bribery," Denver University Law Review, 74.

Austen-Smith, D., 1987, "Information and Influence: Lobbying for Agendas and Votes," American Journal of Political Science, 37(3), 799-833.

Baron, D., 2001, "Private Politics, Corporate Social Responsibility and Integrated Strategy," Journal of Economics \& Management Strategy, 10, 7-45.

_ and D. Diermeier, 2005, "Strategic Activism and Non-Market Strategy," Mimeo, Stanford Graduate School of Business.

Bennedsen, M. and S. Feldmann, 2002, "Lobbying Legislatures," Journal of Political Economy, 110(4), 919-946.

Bernheim, D. and M. Whinston, 1986, "Menu Auctions, Resource Allocation and Economic Influence," Quarterly Journal of Economics, 101(1), 1-31.

Buchanan, J.M., R.D. Tollison, and G. Tullock, Eds., 1980, Toward a Theory of the Rent Seeking Society, College Station: Texas A\&M University Press.

Cho, I-K. and D. Kreps, 1987, "Signaling Games and Stable Equilibria," The Quarterly Journal of Economics, 102(May), 179-222.

Chwe, M., 1990, "Why Were Workers Whipped? Pain in a Principal-Agent Model," Economic Journal, 100(403), 1109-1121.

Dal Bó, E., 2000, “Bribing Voters," Working paper \#39, Department of Economics, University of Oxford, American Journal of Political Science, forthcoming.

— and R. Di Tella, 2003, “Capture by Threat," Journal of Political Economy, 111(5), 11231154.

— P. Dal Bó, and R. Di Tella, 2006, "'Plata o Plomo?': Bribe and Punishment in a Theory of Political Influence," American Political Science Review, 100(1), 41-54.

Fudenberg, D. and D.K. Levine, 1981, "Reputation and Equilibrium Selection in Games with a Patient Player," Econometrica, 57(July), 59-78. 
_ and J. Tirole, 1991, Game Theory, Cambridge, MA: MIT Press.

Gambetta, D., 1993, The Sicilian Mafia: The Business of Private Protection, Cambridge, MA: Harvard University Press.

Garfinkel, M., 1990, "Arming as a Strategic Investment in a Cooperative Equilibrium," American Economic Review, 80, 50-68.

Grossman, G. and E. Helpman, 1994, "Protection for Sale," American Economic Review, 84, 833-850.

Helpman, E. and T. Persson, 2001, "Lobbying and Legislative Bargaining," Advances in Economic Analysis \& Policy, 1(1).

Hirshleifer, J., 2001, The Dark Side of the Force: Economic Foundations of Conflict Theory, Cambridge, UK: Cambridge University Press.

Konrad, K. and S. Skaperdas, 1997, "Credible Threats in Extortion," Journal of Economic Behavior and Organization, 33, 23-39.

Kreps, D., P. Milgrom, J. Roberts, and R. Wilson, 1982, “Rational Cooperation in the Finitely Repeated Prisoner's Dilemma," Journal of Economic Theory, 27, 245-252.

— and R. Wilson, 1982, "Reputation and Imperfect Information," Journal of Economic Theory, 27, 253-79.

Landes, W. and R. Posner, 1975, "The Private Enforcement of the Law," Journal of Legal Studies, 4(1), 1-46.

Leaver, C., 2002, "Bureaucratic Minimal Squawk: Theory and Evidence," Mimeo, University of Oxford.

— and M. Makris, 2001, "Passive Industry Interests in a Large Polity," Mimeo, University of Oxford.

Lindgren, J., 1988, "The Elusive Distinction between Bribery and Extortion: From the Common Law to Hobbes," UCLA Law Review, 35

Mailath, G. and L. Samuelson, 2006, Repeated Games and Reputation: Long Run Relationships, Oxford, UK: Oxford University Press.

Milgrom, P. and J. Roberts, 1982, "Predation, Reputation, and Entry Deterrence," Journal of Economic Theory, 27, 280-312.

Powell, R., 1993, "Guns, Butter, and Anarchy," American Political Science Review, 87(1), $115-132$.

Ramseyer, J.M. and E. Rasmusen, 1992, "Cheap Bribes and the Corruption Ban: A Coordination Game Among Rational Legislators," Public Choice, 78(3-4), 305-327.

Rosenthal, R., 1981, “Games of Perfect Information, Predatory Pricing, and the Chain-Store Paradox," Journal of Economic Theory, 25, 92-100.

Shavell, S. and K.E. Spier, 2002, "Threats Without Binding Commitment," Topics in Economic Analysis \& Policy, 2(1), Article 2.

Skaperdas, S., 1992, "Cooperation, Conflict, and Power in the Absence of Property Rights," American Economic Review, 82, 720-739.

Sloof, R. and F. van Winden, 2000, "Show Them Your Teeth First! A Game-Theoretic Analysis of Lobbying and Pressure," Public Choice, 104, 81-120.

Smith, A. and F. Varese, 2001, "Payment, Protection and Punishment: The Role of Information and Reputation in the Mafia," Rationality and Society, 13, 349-393.

Stigler, G., 1971, "The Theory of Economic Regulation," Bell Journal of Economics and Management Science, 2(1), 3-21.

Tullock, G., 1997, “Where Is the Rectangle?" Public Choice, 91(April), 149-159.

Varese, F., 1994, "Is Sicily the Future of Russia?: Private Protection and the Rise of the Russian Mafia, Archives Europeenes de Sociologie, 35(2), 224-259. 